\title{
Anemia due to Chronic Disorder
}

National Cancer Institute

\section{Source}

National Cancer Institute. Anemia due to Chronic Disorder. NCI Thesaurus. Code C35659.

Anemia due to a disorder that is persistent or long-standing in nature. 